\title{
Louisa Burns Memorial Lecture: Research in Residencies
}

DANIEL H. BELSKY, DO

Stratford, New Jersey
I am honored to have the opportunity to speak to you today on the subject of research in residencies in the name of a great lady. Louisa Burns died at the age of 88 in Whittier, Calif, in January 1958, when I was an intern. During my entire career, I was to hear much about this outstanding osteopathic physician. In trying to find out more about her, I learned that she had become a school teacher in Ohio after receiving her BS degree at the Borden Institute in Indiana and that while a teacher, she had severe spinal meningitis that did not respond to the therapy offered. Her family moved her to Los Angeles, where she experienced a miraculous recovery after receiving osteopathic manipulative treatment.

Owing to the influence of Dr George Burton, Louisa Burns decided to enter the osteopathic profession. She studied at the then Pacific College of Osteopathy, from which she received her DO degree in 1903 and her Doctor of Science degree in 1906. She had gone back to the Borden Institute for her MS degree and returned to Pacific College as a teacher and clinician. In 1916, Dr Burns was named director of the A. T. Still Research Institute in Chicago, which in 1936 was incorporated into the AOA National Research Program to form the A. T. Still Osteopathic Foundation and Research Institute. From 1918 until her retirement in 1957, Dr Burns headed the Institute's research laboratories at Sunny Slope, Calif, then in Los Angeles.

Dr Burns was an honorary life member of the American Osteopathic Association. She devoted her entire career to research in osteopathic medicine, her areas of interest being osteopathic principles, mold biology, and the physiology of the nervous system. She published several books, including $B a$ sic Principles, The Nerve Centers, The Physiology of Consciousness, Cells of the Blood, and Pathogenesis of Visceral Disease following Vertebral Lesions. She received many honors from our profession: in 1928 , she was awarded the distinguished service

Dr Belsky is professor and chairman, Department of Obstetrics and Gynecology, University of Medicine and Dentistry of New Jersey-School of Osteopathic Medicine, Stratford, NJ.

Reprint requests to Daniel H. Belsky, DO, 301 South Central Plaza, Suite 2500, Stratford, NJ 08084-1504. certificate by the AOA; in 1950, a research laboratory in the Los Angeles school was named for her; in 1969, the Louisa Burns Memorial Lecture was established.

\section{Personal experience in research in residencies}

Let me tell you a little about myself and my involvement in research in residencies. In 1953, I entered the Philadelphia College of Osteopathic Medicine (PCOM), where I was exposed to some of the great minds of our profession. Dr Angus G. Cathie was the chairman of the extremely talented department of anatomy. He made osteopathic medicine a part of applied anatomy. He brought to life the importance of disease states as they relate to anatomic function. Dr Edwin H. Cressman was professor of histology; Dr Blanche Clow Allen, a prosector in anatomy; and Dr William Baldwin, Jr, professor of physiology. Dr Baldwin made physiology a comparative science in terms of pathophysiology; and the study of that science, a dynamic experience. He is well remembered for his case presentations, in which he brought applied physiology to the lecture room. Many of us who had the privilege of studying under him are forever grateful.

I also studied under Dr James M. Eaton, a nationally known orthopedic surgeon and chairman of the Department of Surgery. Dr Eaton applied osteopathic skills to his specialty and made sure that we interns and residents were giving treatments postoperatively and that we understood the reasons why. Dr Frank E. Gruber was my chief and my role model of the solid, unemotional, involved, and caring physician. Studying under him in the operating and delivery rooms and wishing to emulate him, I learned the osteopathic approach to obstetrics and gynecology.

One person stands out in my mind above all the rest of the great teachers to whom I was exposed: Mrs Frances Bisel, our medical librarian. It was Mrs Bisel who taught me how to do a research project, how to use the library. In those days, as many of you will remember, we had manual retrieval of charts. I had had some experience in research as an undergraduate at Temple University but had not become involved in research at any level at PCOM. During my residency there, I was allowed 
to apply for a Master of Science degree in obstetrics and gynecology and to submit an original research paper. Mrs Bisel directed me to the sources I needed; she encouraged me to use the library at the College of Physicians and Surgeons in Philadelphia; she taught me how to refine my technique in developing a bibliography. Largely through her guidance and encouragement, I was awarded my Master of Science degree in 1961.

During my residency, then, I did original research and published a paper on pelviencephalography of the primigravida. At that time, in the late $1950 \mathrm{~s}$, a woman in her first pregnancy was routinely offered an x-ray to determine whether her pelvis was adequate for the size of the fetus. Depending on the results of the pelviencephalogram, it was determined in advance whether the patient would have a vaginal delivery or a cesarean section because of cephalopelvic disproportion. In a study of several hundred cases, we found that patients who had had pelviencephalograms were more likely to have cesarean deliveries than those who had not. My work and that of others in the field at that time helped to change the way in which obstetrics and gynecology were practiced. Pregnant patients and their fetuses are no longer exposed to needless radiation and its sequelae.

When I was a resident, I was always in need of money to supplement my salary. The DO magazine was offering $\$ 25$ per interesting case report, so I sent in as many articles as I could. That experience taught me how to develop a case presentation and submit it for publication.

Dr Gruber allowed me to expand my educational experience by attending lectures and conferences at neighboring institutions in the Philadelphia area. At Thomas Jefferson University, I was exposed to internationally known researchers in obstetrics and gynecology. As a result, I felt a greater need to broaden my vision as a physician. The need was there, but the opportunity was not.

In 1961 when I finished my residency, there were no full-time faculty opportunities in the osteopathic medical profession. Consequently, I went into private practice and did not pursue my interest in the academic world or in research at that time. I did, however, continue my research interest as a private practicing physician until 1979 , when I became a full-time faculty member at the University of Medicine and Dentistry of New Jersey-School of Osteopathic Medicine.

In the early 1970 s, laparoscopy was an exploding area in gynecology. I published papers on the complications of laparoscopy and extensively on pel- vic inflammatory disease as it related to laparoscopic diagnosis. I found that the presumptive diagnosis was correct in only $65 \%$ of the cases in which patients were admitted to the hospital with suspected pelvic inflammatory disease. What was important, however, was that in the misdiagnosed cases, life-threatening situations may have existed. A comparison of my work with studies reported in the literature revealed that other investigators, particularly in Germany and Japan, were finding the same thing.

More recently, I have been studying an area of complication in laparoscopy in the laboratory. In 1987, I had attended an international conference on sterilization in Virginia. There, I became involved in discussions with physicians from countries throughout the world who were concerned that thermal cauterization during tubal sterilization through the operating telescope might cause ancillary bowel burns if the cauterized tube touched the bowel. To establish the validity of their concern, I went into the laboratory with one of my interested residents. Using an animal model, we showed that a bowel burn did not occur as a secondary result of thermal cauterization of the tube.

In 1974, I was instrumental in bringing fetal monitoring to the state of New Jersey. With other personnel from our institution, I designed a computer program to retrieve information on fetal abnormalities. From that program, some 15 research papers were generated. In the one of which I am proudest, published in the September 1979 issue of JAOA, ${ }^{1}$ we reported on the largest series of consecutive fetal-monitored patients in the world. We had a commitment to excellence and a commitment to research and publication in the area of fetal monitoring.

With the help of the computer program, I was able to expand my interest in teenage pregnancy. My residents and I conducted the first study on nonurban teenage pregnancy. At the AOA Research Conference in Chicago in 1981, I presented some of our initial data. These data showed that there was no difference in maternal or fetal outcome in nonurban teenagers compared with a matched group of nonteenagers. These findings are different from those for inner-city teenagers. Our university has a large grant from the National Institutes of Health to study pregnant inner-city adolescents and evaluate their nutritional needs. We are finding that there is a nutritional deprivation in the inner-city population that correlates with intrauterine growth retardation and with prematurity. We have published several papers recently 
under the direction of Theresa O. Scholl, $\mathrm{PhD} .^{2-11}$

I am proud that we established the first in vitro fertilization-embryo-transfer program in the profession, with several successful pregnancies. Our program is now being upscaled: using vaginal ultrasound guidance, we will be performing ovum retrieval.

I have reported on my experience with induction of labor, showing that elective induction of labor is safe in comparison with indicated induction, oxytocin augmentation, or no oxytocin at all.

\section{The role of the AOA in research development}

What is the role of the AOA in the development and support of research in osteopathic residencies in today's environment? In 1986, as a member of the Committee on Postdoctoral Training of the AOA, I proposed a resolution that all residency programs have a research component. The committee passed the resolution and asked the Board of Trustees to enact it. In 1987, the Board acted favorably on this request; and today our basic residency documents direct the need for research in the residency program.

This acknowledgment of the Board of Trustees of the need for research has filtered down to the specialty colleges. My own, the American College of Osteopathic Obstetricians and Gynecologists, holds research as a part of its basic document and clearly spells out what the research component is to be. The AOA is in the process of instituting the Clinical Investigator Fellowship. The Bureau of Research has developed a protocol that will offer funding for residents who are interested in becoming primarily researchers. The AOA is also involved in helping fund osteopathic research. Dr Howard Levine has been very instrumental in bringing about a dues increase, a portion of which will be allocated for research funding.

We in the AOA have a problem to which we must address ourselves-namely, the attitudes of some of our residency training leaders toward research. It is difficult to change the mind set of a group of physicians: some oppose change; they want things to remain mostly as they are. Through education and possibly exposure to more seminars like those being sponsored at this convention by the Bureau of Research, we may be able to persuade many of our leaders in osteopathic residencies of the importance of research in our programs.

\section{The role of osteopathic institutions}

What is the role of institutions in promoting research in residencies? We have to look to the col- leges and in some instances to the hospitals. It behooves us at the college level to develop full-time faculties, not just volunteer faculties, in the specialties. In the various disciplines, we must have full-time persons who are committed to furthering the research component of their specialties. We have to have more full-time scientists- $\mathrm{PhDs}$ and DOs-in the various clinical departments. I am pleased to have two full-time PhDs in my department. It has benefited my residency program to have my residents involved with $\mathrm{PhD}$ faculty members in the performance of research. We should develop a network of facilities for our residents.

The best example I can give is the Suburban General Hospital in Norristown, $\mathrm{Pa}$. An excellent resident in obstetrics and gynecology was in its program. She was very bright and interested in research, but she had no laboratory facilities. Suburban General Hospital arranged with PCOM for the laboratory research component of her residency. As a resident, she was to present three award-winning papers, based on laboratory research made possible through the cooperation of the two institutions. We as a profession, and especially we who are involved in residency training, must encourage our strong institutions to share their research facilities with institutions that lack them so that a hospital-based residency can now coordinate with the college-based facility.

We can no longer tolerate vocational residencies; we must have academic programs. We must look toward the future and develop more meaningful, research-oriented programs. Institutions have to create a research environment: it has got to be the thing to do; it has got to be fun; it has got to be a part of our existence in the institution.

Institutions should become identified with particular areas of research. For example, our school, through our department, is becoming identified with Doppler flow studies, fetal electrocardiography, and fetal cardiac ultrasonography. We are becoming known as the place to send that difficult case. As the Mayo Clinics, the Harvards, and the Yales are associated with certain areas of medical research, our osteopathic institutions must likewise be associated with particular research specialties.

\section{The role of specialty colleges}

The basic documents of the specialty colleges should contain very specific outlines of their expectations of the residents during the programs. The colleges should develop thesis awards. Let us reward excellence; let us get the best papers and 
publicize them in national forums. The specialty colleges should be involved in obtaining grants for original research; being the experts, they have to review research performance and critique the residents' work.

\section{The role of the program director}

The program director in an osteopathic research program should, most importantly, serve as a role model for the resident. The program director must be interested in research, must share that interest with the resident, must be involved in the resident's research project, and must continually review it with the resident. The director might also appoint a faculty member to each resident for the purpose of overseeing the research project and acting as an advisor.

The program director should establish a research rotation. Our program, with 11 residents, has rotations in clinics, obstetrics, perinatology, gynecologic oncology, reproductive endocrinology, and research. The research segment is spent in the laboratory.

The program director has to evaluate his institution and establish a level of research, consistent with the capabilities of his faculty and staff. With the help of others, he has to involve himself with the funding of projects.

\section{The role of the resident}

Residents do not play a major role in establishing research; they come to us as neophytes seeking to be taught. It is the institution, the AOA, and the program director who must take the resident and help develop his or her research interests. The resident should be encouraged to develop an interest in an area that he or she can carry on throughout the residency research experience.

When a resident comes into a program, the director has the responsibility as an educator to make that person the very best specialist that he or she can be.

\section{Designing osteopathic research in a residency}

In 1987 , I was asked to be the keynote speaker at a workshop sponsored by the Committee on Postdoctoral Training (COPT) on "The Future of Osteopathic Residencies." I would like to summarize some of the thoughts I expressed in that address:

Wordsworth described poetry as the spontaneous overflow of powerful emotion recollected in tranquility. If poetry is the artistic expression of an emotion, then research is the scientific expression of an idea. In his monumental novel The Shoes of the Fisherman, Morris West said the most explosive thing in the world is an idea. Literature can best be described as creativity in its purest, freest form; and research, as creativity within defined guidelines.

The searching mind gives birth to an idea; the idea is the fundamental basis of knowledge. From an idea, hypotheses are formed, tested, and eventually proved or disproved.

At its July 1987 meeting, the AOA Board of Trustees adopted a resolution directing all residency training programs to make a research component an integral part of their basic documents and to submit revised basic documents to the COPT for review in the spring of 1988 . Our profession recognizes its commitment to excellence and the Board of Trustees is helping set the tone for the future direction of osteopathic medicine.

I ask that we consider the following basic premises concerning osteopathic medical research. First that it requires a college or university setting offering laboratory facilities, grantsmanship, and funding. Let us consider expanding this concept to include as settings affiliated or college-owned hospitals. Second, research requires the presence of basic scientists or clinical scientists, both $\mathrm{PhDs}$ and DOs. Some controversy exists about whether osteopathic research needs definition. Any definition forthcoming should be simple, universal, and applicable. Osteopathic research should apply to all clinical investigation, not only to that of the classical osteopathic lesions. Indeed, there is an osteopathic component to the study of most clinical entities. For example, the study of the ejection fraction of the left ventricle includes anatomic, physiologic, and pathologic aspects. In designing osteopathic research, the less specific surgical trials model may be more applicable than the clinical trials model, with its specific values, biochemical components, and exact measurements.

In researching an aspect of carotid endarterectomy, for example, surgeons do not specify the type of scalpel to be used for the incision, the location of the incision, the length of the incision, the retractors to be used, or the procedure of curettage of the intima of the artery. They do not specify the type of suture to be used for closing the incision or refer to the exacting postoperative care. This type of approach may be preferable in the designing of osteopathic research projects.

\section{Research challenges in residencies}

Our challenges include developing authorities in specific areas of medicine and becoming identified 
with particular areas of expertise. We must share more of the things that we are doing. We must publish our experience more widely. When we report at a national conference, we should report on our own work and not on the work of others, not on a review of the literature, not on an interesting case. Let us present our own series of cases and then compare our findings with those reported in the literature. We have to continue to build our osteopathic medical heritage as we build our research heritage, and we have to do so in today's environment of cost containment and managed healthcare.

The greatest threat to the development of osteopathic medical research in our residency programs is the current difficulties in obtaining funding. When we meet at the Bureau of Research, we agonize over the lack of available funds; therefore, we have to be very specific about how we design our research projects. Hospitals are deemphasizing affiliation with osteopathic medical schools because of the increased expense of house staff and tertiary services; HMO dollars are now being directed more toward nonaffiliated hospitals, a policy that is less expensive. At the moment, the largest HMO in New Jersey is saying that it does not want to use the Kennedy Memorial Hospital-University Medical Center in Stratford, NJ, because it is not cost effective to do so. That means that most of the state of New Jersey could be denied osteopathic medical care in hospitals.

\section{The future of research in the residencies}

I see myself as a transitional researcher-a clinician, not a laboratory person. I think that I am one of the people in our profession who is bridging the gap and who is able to recognize the needs the future holds for our young investigators. We who are in this position have to look toward the next generation of DO researchers, a generation that will spend minimal time in clinical practice. The profession must develop the basic documents that will accommodate these researchers and make it worthwhile and exciting to enter research.

We will have to have more basic scientists and more science-oriented people on the faculties of our specialty departments. We will have to strengthen our existing research centers through increased funding, faculty development, and continued sponsorship of centers of excellence. We will have to continue to support the AOA at all levels in the development of the Clinical Investigator Fellowship program. We will have the further responsibility of seeking out those persons entering our schools who are interested in research.
In reviewing today the respective roles of the $\mathrm{AOA}$, the institution, the program director, and the resident, my prevailing message has been that we must have program directors who are committed to excellence and to the continued development of osteopathic medical research in their residency programs.

Finally, I leave you with these questions: Who will the world remember better, the great soprano or the great composer? the great performer or the great playwright? the great model or the great artist? I believe that the world will remember Jonas Salk better than it will the many pediatricians who administer his vaccine. It was Rudyard Kipling who said,

"I keep six honest serving-men

(They taught me all I knew);

Their names are What and Why and When

And How and Where and Who."

1. Belsky DH, Cooperstein MS, Fitzgerald DL: Total fetal monitoring: A computerized study. JAOA 1979;79:21-30.

2. Scholl TO, Hediger ML, Ances IT: Maternal growth during pregnancy and decreased infant birth weight. Am J Clin Nutr 1990;51:790-793.

3. Steer RA, Scholl TO, Beck AT: Revised Beck Depression Inventory scores of inner-city adolescents pre and postpartum. Psychol Rep 1990;66:315-320.

4. Hediger ML, Scholl TO, Belsky DH, et al: Patterns of weight gain in adolescent pregnancy: Effects on birth weight and preterm deliver. Obstet Gynecol 1989;74:6-12.

5. Scholl TO, Hediger ML, Vasilenko P III, et al: Effects of early maturation on fetal growth. Ann Hum Biol 1989;335-345.

6. Scholl TO, Hediger ML, Salmon RW, et al: Association between low gynaecological age and preterm birth. Paediatr Perinatal Epidemiol 1989;3:357-366.

7. Hediger ML, Scholl TO, Salmon RW: Early weight gain in pregnant adolescents and fetal outcome. Am J Hum Biol 1989;1:665-672.

8. Scholl TO, Hediger ML, Salmon RW, et al: The influence of prepregnant body mass and weight gain for gestation on spontaneous preterm delivery and duration of gestation during adolescent pregnancy. Am J Hum Biol 1989:1:657-664.

9. Karp RJ, Scholl TO, Decker E, et al: Growth of abused children contrasted with the non-abused in an urban poor community. Clin Pediatr (Phila) 1989;28:317-320.

10. Scholl TO, Salmon RW, Miller LK, et al: Weight gain during adolescent pregnancy: Associated maternal characteristics and effects on outcome. J Adolesc Health Care 1988;9:286-291. 11. Scholl TO, Johnston FE, Cravioto J, et al: The utility of cross-sectional measurements of weight and length for age in screening for growth failure (chronic malnutrition) and clinically severe protein-energy malnutrition. Acta Paediatr Scand 1983;72:867-873. 